\title{
A Train-Mounted GPR System for Operating Railway Tunnel Inspection
}

\author{
Hongqiang XIONG ${ }^{\mathrm{a}, \mathrm{b}, 1}$, Guofeng $\mathrm{SU}^{\mathrm{b}}$, Chunliu ZHANG ${ }^{\mathrm{b}}$, Baoqing $\mathrm{LI}^{\mathrm{b}}$, and Wentao \\ WEI $^{\mathrm{b}}$ \\ ${ }^{a}$ Faculty of Geosciences and Environmental Engineering, Southwest Jiaotong \\ University, Chengdu, 610036, China \\ ${ }^{\mathrm{b}}$ Southwest Jiaotong University Research Institute (Chengdu) Co., Ltd, Southwest \\ Jiaotong University, Chengdu, 610036, China
}

\begin{abstract}
With the increasing number and aging of railway tunnels, regular inspection will be an important means to ensure the safety for operation railways. A train-mounted ground penetrating radar system with cores of air-coupled antennas and shared time-window model has been developed to allow for longdistance and fast inspection of tunnels. The system consists of 6 groups of aircoupled antennas with center frequency of $300 \mathrm{MHz}$. The distance between antenna and lining is $0.5-4.0 \mathrm{~m}$, the scanning rate of the system is $976 \mathrm{scans} / \mathrm{Sec}$ and the detection depth of the GPR can reach to $2.5 \mathrm{~m}$. Under the theoretical design, the maximum speed of train can reach $70.27 \mathrm{~km} / \mathrm{h}$ with a scan interval of $0.02 \mathrm{~m}$. The test results on Shenyang-Dandong railway passenger dedicated line show that the system can identify the thickness of lining, the void and the backfill state behind lining.
\end{abstract}

Keywords. Ground penetrating radar, railway tunnel, regular inspection, aircoupled antennas

\section{Introduction}

Regular inspection is the trend of railway tunnel maintenance. There are some quality defects in the construction process of the tunnel, as well as diseases caused by material and geological changes in the operation process. The increase of the service life further aggravates the aging and disease of tunnels, endangering the traffic safety. Undoubtedly, railways, highways and subways face the same problems that aging and disease of operating tunnels are already a worldwide problem.

In 1999, three railway tunnel spalling accidents occurred in Japan. On June 27, concrete spalling occurred in Fukuoka tunnel of Sanyo Shinkansen (Bullet Train) line, and a $200 \mathrm{~kg}$ concrete hit the high-speed train; on October 9, the KitaKyushu Tunnel occurred a concrete spalling accident; on November 28, a 2 tons concrete spalling occurred at the arch of the Rebunhama Tunnel, causing the freight train Derailment [1]. On December 2, 2012, an accident of tunnel ceiling collapse took place in the Sasago Tunnel on the Central Expressway, killing 9 people [2]. In 2006, a concrete slab of the Boston central tunnel project collapsed in the USA, with a concrete weight of 12 tons

\footnotetext{
${ }^{1}$ Hongqiang XIONG, Southwest Jiaotong University Research Institute (Chengdu) Co., Ltd, 111 North Section 1 of the Second Ring Road, Chengdu 610036, China; E-mail: 1014007697@qq.com.
} 
[3]. In 2017, the rail tunnel collapse near the German town of Rastatt in the Rhine Valley, which known as the 'Rastatt-incident', caused a loss of $€ 2.048$ billion to rail freight-based logistics chains [4]. In 2017, several tunnels on the Guizhou section of the Shanghai-Kunming high-speed railway, which was open to traffic for less than a year, sprayed water, causing a large area of train suspension.

Nowadays, the GPR (ground penetrating radar) is one of the most popular nearsurface geophysical methods adopted for disease of tunnel lining, which can survey different kinds of lining, such as reinforced concrete, unreinforced concrete, sprayed concrete, except shotcrete containing steel fibres [5]. When the GPR system works, the antenna moves close to the lining surface. Some researches on the application of GPR in the inspection of hidden targets in tunnel lining have achieved practical results, including concrete thickness [6], voids [7], discontinuities and compactness between concrete and rock face or inner lining [8-10], water seepage [11, 12], rebar cover and location $[13,14]$.

Although GPR has a good effect in tunnel lining condition monitoring, the biggest problem of GPR survey in tunnels is difficult implementation like traffic disruption, fitting of the antenna on tunnel lining, and obstruction of metal catenary structure running. Traditional GPR technology mainly relies on manual hand-held or hydraulic support to make the radar antenna close to the lining wall for detection. The time is wasted due to the repeated installation of detection devices and moving antennas, so the detection speed is similar to walking. As of the end of 2019, the length of railway tunnel in China reached $18,041 \mathrm{~km}$ with a total number of 16,084, including 3,442 high-speed railway tunnels with a length of 5,515 km [15]. Traditional GPR methods cannot meet the requirements of regular health inspection for the national railway network.

Aiming at the huge number of operating railway tunnels in China, the need for regular inspection and the slowly detecting speed of traditional GPR system, a trainmounted GPR system for operating railway tunnels is developed. It enables the test to be carried out continuously at high speed. In this paper, how to design the system and how to test the system on the railway line will be discussed, which provide insights for the design of GPR and its application in tunnel.

\section{The Key Design of the GPR for Railway Tunnel}

Different from other types of tunnels, railway tunnels has two obvious characteristics: First, it has one or more rails already installed, which ensures that the distance between antennas and the lining surface is relatively fixed during operation. Second, a large number of metal catenary structures exist at the top of the tunnel. Obviously, the former is beneficial to GPR, while the latter needs to be avoided. In order to detect tunnel at the normal speed of the train, two key issues need to be resolved. One is how to avoid metal catenary; the other is the working speed and efficiency of GPR system.

\subsection{The Air-coupled Antenna}

Bow-tie antennas are the first choice of the ground-coupled antennas of impulse GPR (as shown in Figure 1(a)). Its typical characteristics are small size, and almost all radiation energy can be radiated to the structure of the detected object due to contact or close to the surface of the measured target [16]. But it has three shortcomings. 
- The detection speed of GPR system is slow.

- Uneven lining surface and man-made unsteady operations will affect the test seriously.

- The lining is located in the near-field. The direct wave and the near field effect form a "blind zone" of about 1.5 times the wavelength, so it is difficult to distinguish the anomalies of the shallow lining [17].

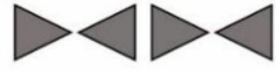

(a)

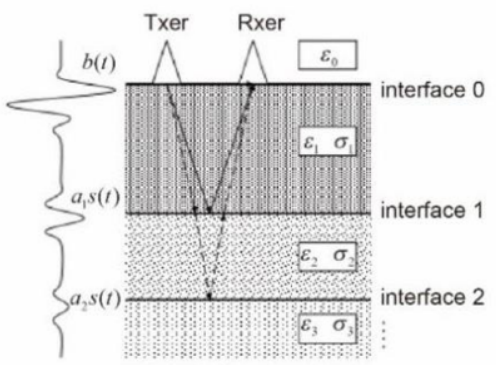

(c)

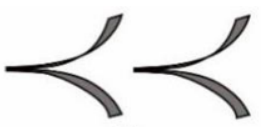

(b)

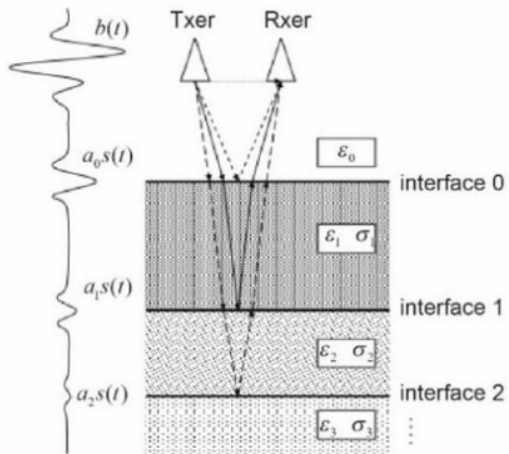

(d)

Figure 1. The ground-coupled and air-coupled antenna (a) Bow-tie antennas (b) TEM antenna (c) Working principle of ground-coupled antenna (d) Working principle of air-coupled antenna.

An ultra-wide band transverse electromagnetic (TEM) horn antenna is designed and applied to this system (Figure 1(b)). Figure 1(c)and Figure 1(d) shows the difference between the air-coupled antenna and the ground-coupled antenna [18]. On the one hand, when the air-coupled antenna is more than 1.5 times the wavelength from the lining surface, the direct wave is separated from the lining surface, and the reflection of the lining surface (Figure 1(b), interface 0) is obvious. On the other hand, due to the spherical diffusion attenuation, a part of the electromagnetic wave energy will be lost in the air. The reflected signal amplitudes of interfaces 1 and 2 in Figure 1(d) are smaller than those in Figure 1(c).

Considering the energy attenuation caused by the distance between the antenna and the lining and the frequency needed to detect the lining, an air-coupled antenna with center frequency of $300 \mathrm{MHz}$ was fabricated. A pulse source up to $300 \mathrm{~V}$ was made to solve the problem of energy reduction and the echo of the train-mounted GPR system can reach up to $750 \mathrm{mV}$.

\subsection{The Timing Diagram of System}

To achieve faster detection speed and higher detection efficiency, the timing design of system is the key to design. The design shown in Figure 2 is used to complete the mutual independence of the 6-channel system, and the GPR system can detect 6 measuring lines in each test. 


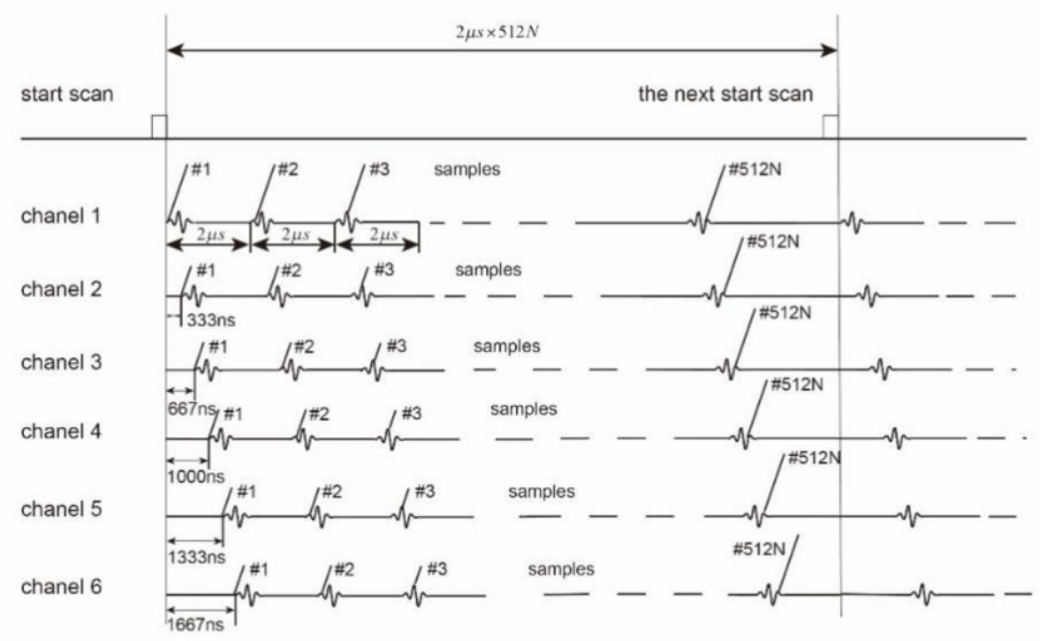

Figure 2. The timing diagram of the 6-channel system.

As shown in Figure 2, a time window of 2000 ns is shared equally to 6 channels. Theoretically, the maximum time window of each channel is $\approx 333 \mathrm{~ns}$, and there is $333 n s$ delay between two adjacent channels. When the system is running, each channel completes A-scan according to the delay. The time window of each channel can be taken as $0 \sim 333 \mathrm{~ns}$, and the scanning speed of the system is:

$$
S=\frac{1 \times 10^{9}}{512 \times N \times 2000} \text { scans } / \text { Sec }
$$

According to the different measuring-point spacing $\Delta d$, the scanning speed of the system is as follows:

$$
V_{M A X}=\Delta d \times S \times 3.6 \mathrm{~km} / \mathrm{h}
$$

512 is the minimum number of samples per A-scan, and the maximum scanning speed of the system is 976 scans / Sec. According to $\Delta d=0.02 \mathrm{~m}$ for data collection, the maximum test speed of this GPR system is $\approx 70.27 \mathrm{~km} / \mathrm{h}$.

\section{The Composition and Main Parameters of the Train-mounted GPR System for Operating Railway Tunnel Detection}

The system includes: mechanical support, six-channel GPR system, positioning system and software system, and its picture shown in Figure 3. 


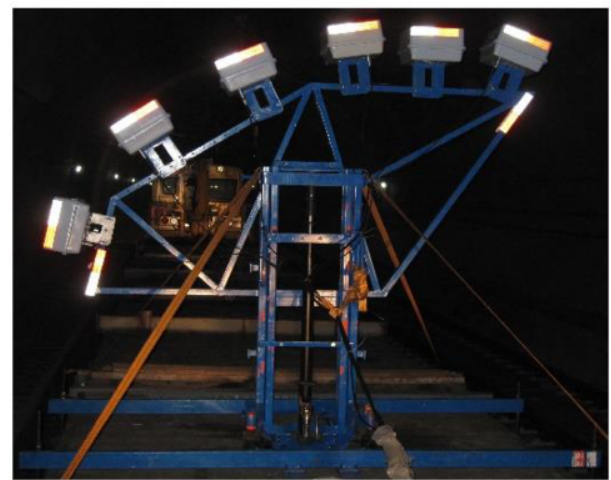

The mechanical support

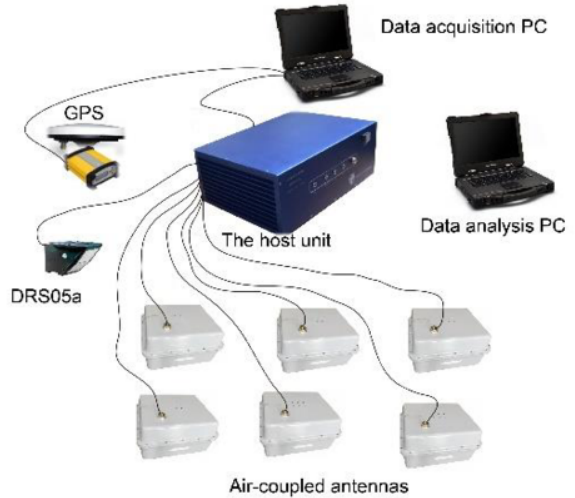

Air-coupled antennas

Figure 3. The train-mounted GPR system.

As shown in Figure 3(a), the mechanical support is made of aluminum alloy, with a weight of about $75 \mathrm{~kg}$, which is easy to disassemble. It can be lifted or lowered by 1.5 $\mathrm{m}$, and installed on any detection vehicle platform larger than $2.5 \mathrm{~m} \times 2.0 \mathrm{~m}$ to support six air-coupled antennas. The system can be used for single-line tunnel full-section detection and double-line tunnel reciprocating full-section detection. Main parameters of the GPR system are shown in Table 1.

Table 1. Main parameters of the train-mounted GPR system

\begin{tabular}{lll}
\hline Parameters & Value & Precondition \\
\hline Channel & 6 & NA \\
Antenna & $300 \mathrm{MHz}$ & NA \\
Time window & $90 \mathrm{~ns}$ & NA \\
Maximum PRF & $976 \mathrm{scans} / \mathrm{Sec}$ & NA \\
Maximum speed & $70.27 \mathrm{~km} / \mathrm{h}$ & Point spacing $0.02 \mathrm{~m}$ \\
Detection distance & $0.5-4.0 \mathrm{~m}$ & The best distance is $1.5 \mathrm{~m}$ \\
Detection depth & $0-2.5 \mathrm{~m}$ & Relative permittivity $5-11$ \\
\hline
\end{tabular}

In working, the resolution and depth of GPR detection are the two most concerned contents. The longitudinal resolution of GPR refers to the minimum thickness that can be resolved in tunnel structure, which is usually considered as $1 / 4$ the wavelength. If the relative permittivity of the lining is 8.0, the longitudinal resolution is about $0.092 \mathrm{~m}$. The horizontal resolution $r$ of GPR refers to the minimum distance that can distinguish two objects. $r$ can be calculated from the following formula:

$$
r=\frac{\sqrt{\lambda h}}{2}
$$

The $h$ is the distance between the antenna and the lining. The detection depth is related to multiple parameters such as the lining material and shape, the distance between the antenna and the lining, and the antenna performance. In tests, the antenna described in this paper can generally detect targets with depth more than $2.5 \mathrm{~m}$ (Figure 4). 


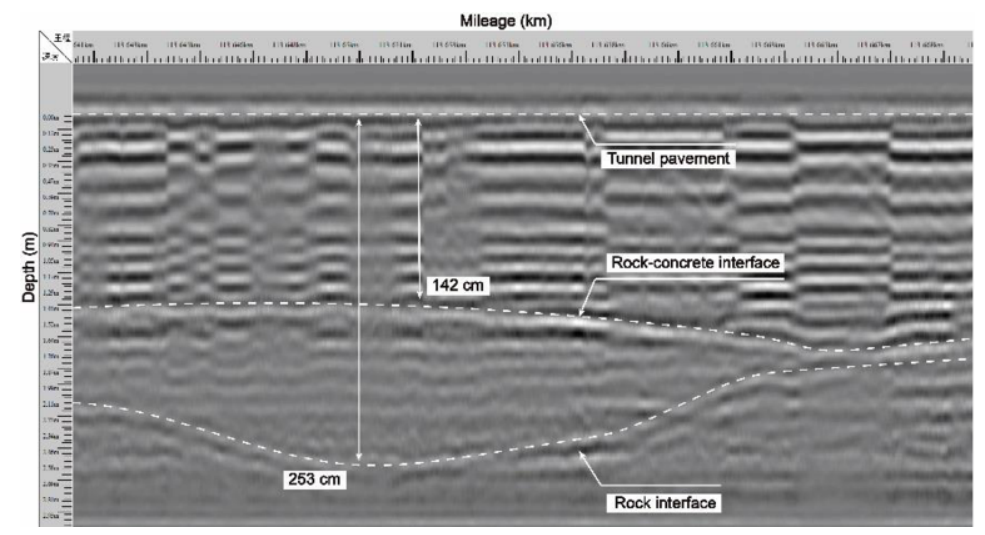

Figure 4. Detection data of Tunnel Pavement.

The positioning system is composed of DRS05a radar sensor and GPS. DRS05a, a Doppler radar, performs basic range measurement, provides radar system mileage signal. GPS corrects the mileage information recorded of the DRS05a by comparing the longitude and latitude of railway tunnel entrance and exit. This method is an automatic and continuous absolute positioning, which does not need any redundant operation in the test, and its positioning accuracy is millimeter level. Due to the existence of the railway track and the precise positioning method, the data of the trainmounted GPR system is highly repeatable. If regular inspections are carried out, the development of tunnel diseases can be tracked.

The software system consists of data acquisition software and data processing software. The former controls the acquisition parameters and data storage of the host computer. When the train stops or starts, it does not need to reset the software parameters. Data acquisition software will automatically store the next data file, when the data file is full to $0.5 \mathrm{~GB}$. This mode makes the data collection only need to be set at the beginning of the test, and does not require the engineers to pay attention to whether the collection process is interrupted. Processing software can display and process 6-channel data at the same time, and save the processing steps and generate a file. With this file, you can use the same processing for any other data. A commonly used process flow is shown in Figure 5.

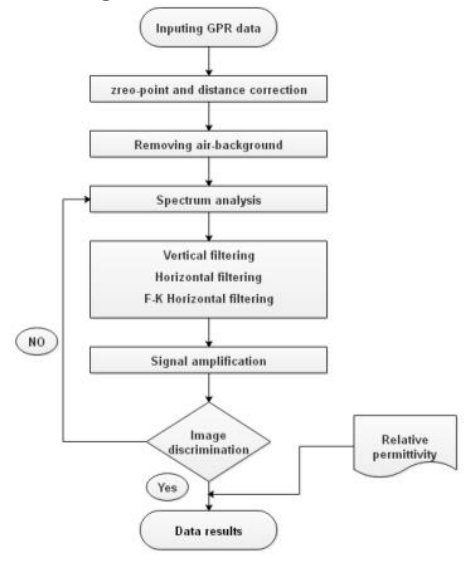

Figure 5. A common flow chart of the data processing. 


\section{Experimental Results}

The railway train-mounted ground penetrating radar system was tested on the Shenyang-Dandong railway passenger dedicated line in December 2018 and February 2019. 66 tunnels were tested with a total length of $90.15 \mathrm{~km}$. In the experiment, the distance between the antenna and the lining surface is $2.0-3.8 \mathrm{~m}$, and the train speed is $40-60 \mathrm{~km} / \mathrm{h}$. The antenna facing the side wall is the closest, and the antenna facing the vault is the farthest. The photos of the site work and the test plan are shown in Figure 6.

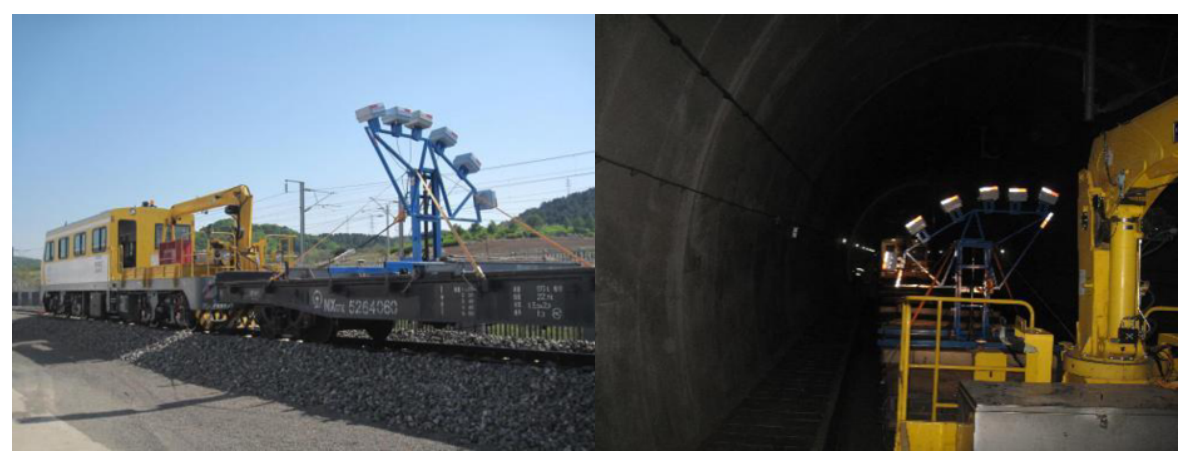

Figure 6. The photos of field work

Figure 7 shows the radar image of the vault from Chengjiapuzi 1\# tunnel. The bottom interface of the lining can be clearly seen in the picture. The thickness of the lining at K115+887 is $28 \mathrm{~cm}$, which is less than the design thickness of $45 \mathrm{~cm}$. This result is close to the $26 \mathrm{~cm}$ review result provided by the Public Works Department.

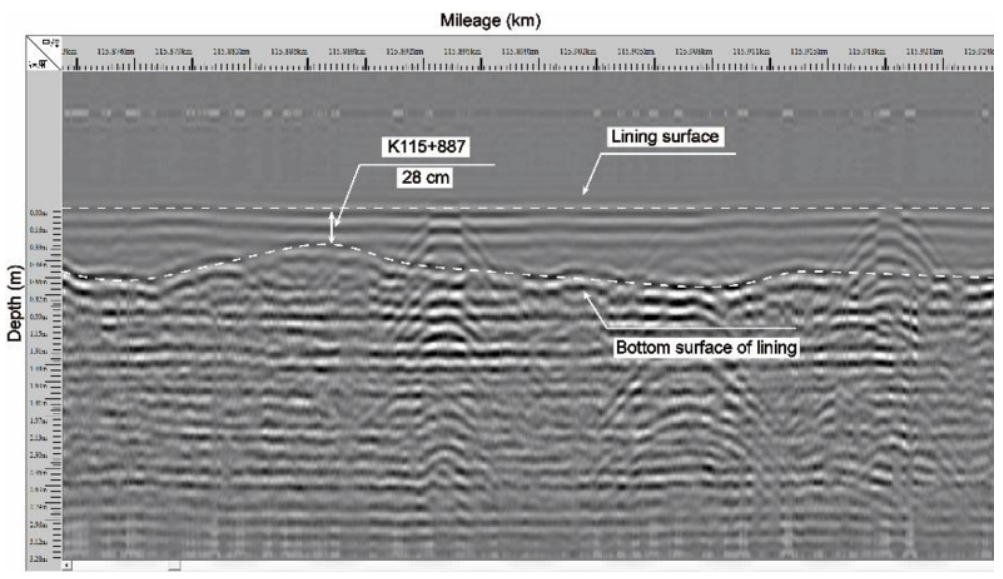

Figure 7. Radar image of lining thickness from Chengjiapuzi 1\# tunnel.

Figure 8 presents the radar image of side wall for Yujialing tunnel, where a large uncompacted backfill area occurred occurred in K107+414 to K107+440. The tunnel was seriously damaged. According to the maintenance records during construction period, grouting was carried out at K107+429 due to uncompacted backfill. Moreover, according to the description of tunnel maintenance workers, the construction joint of $\mathrm{K} 107+418$ side wall has the phenomenon of water seepage and freezing in winter. 


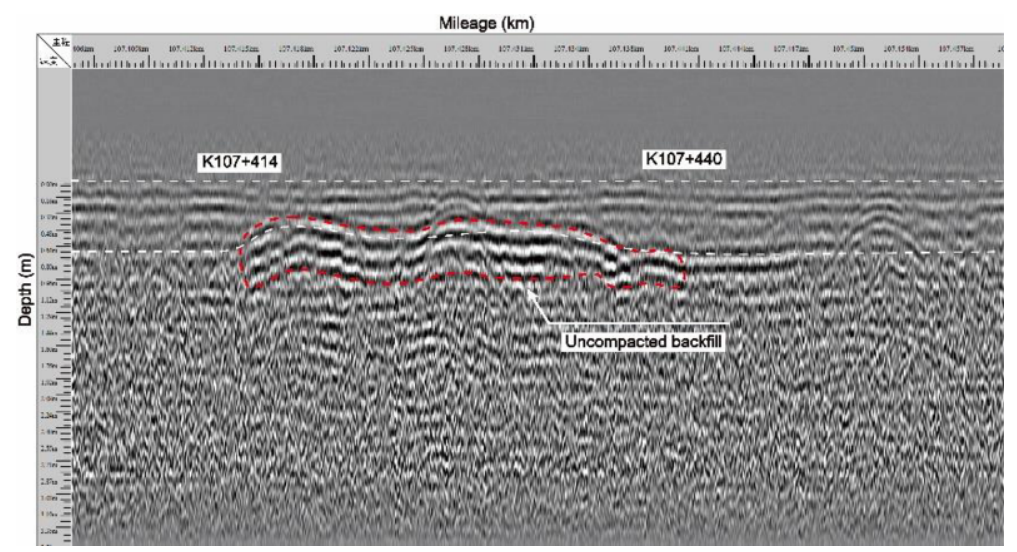

Figure 8. Radar image of uncompacted backfill from Yujialing tunnel.

Figure 9 presents the radar image of arch form upward line of Caojiapuzi tunnel. The K154+125 has a clearly recorded cavity disease with a length of $4 \mathrm{~m}$ in the Shenyang-Dandong tunnel disease database. This disease can be clearly found on the radar image. In this image, the backfill defect at the back of the lining at K154+162 was also scanned by radar.

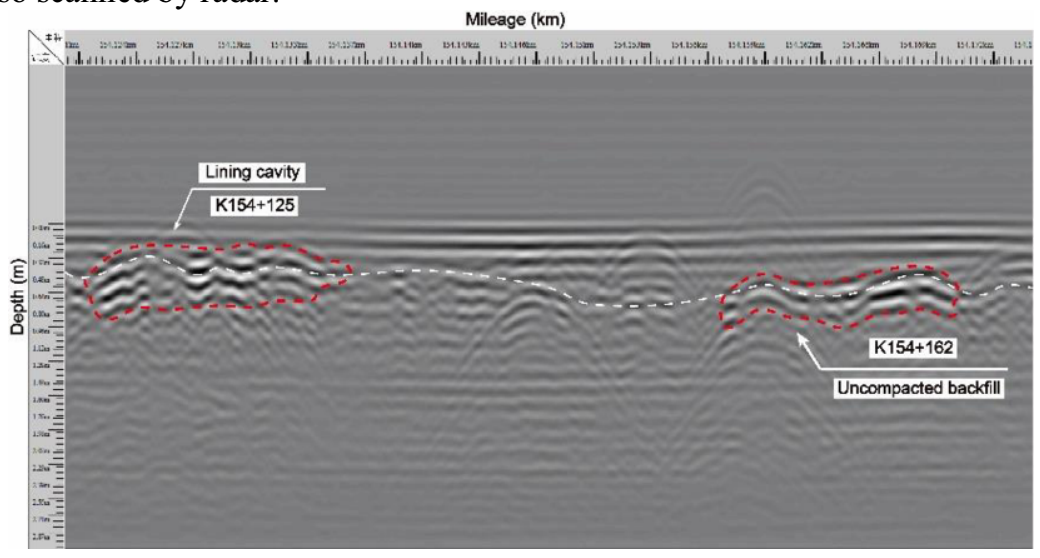

Figure 9. Radar image of lining cavity from Caojiabuzi tunnel.

Through the image detected by the train-mounted GPR, the disease distribution at different locations of tunnel at the same mileage can be analyzed. Figure 10 shows the radar image of the vault and arch waist of the Caojiapuzi tunnel. Near K152+920, maintenance works found obvious signs of construction repair on the lining surface. In the percussion of the vault K152+919 (non-construction joint) and the arch waist K152+921 (construction joint), they found that the skin of the lining fell off (about 3 $\mathrm{cm}$ ), and the waterproof board and waterstop were directly exposed to the air. 


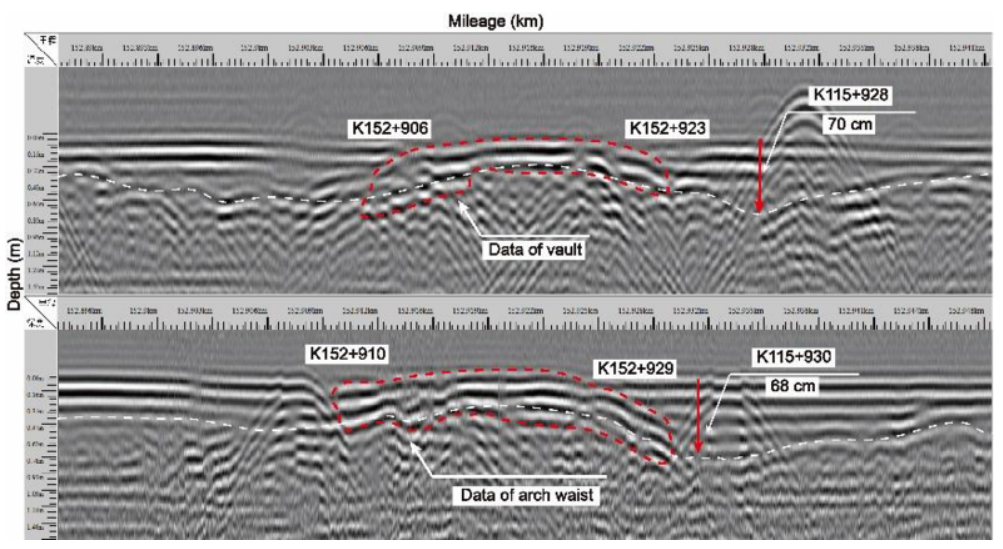

Figure 10. Radar image of different locations from Caojiabuzi tunnel.

Experimental results show that the railway train-mounted GPR system described in this paper can quickly monitoring operating railway tunnel condition, including the thickness of the lining, the void and the backfill state behind the lining.

\section{Discussion and Conclusion}

The operating railway tunnel has trains running for most of day, and the maintenance time is only 2-4 hours. Conventional GPR is difficult to complete the regular health monitoring. A train-mounted GPR system for operating railway tunnels is developed.

The system with cores of air-coupled antennas and shared time-window model. In the train-mounted GPR system, six groups of air-coupled antennas are installed on the vehicle, 0.5-4.0 $\mathrm{m}$ away from the lining surface, and the full-section tunnel physical examination is completed through reciprocating inspection. The system can theoretically reach a speed of $70.27 \mathrm{~km} / \mathrm{h}$ with the scan interval of $0.02 \mathrm{~m}$. On the one hand, the air-coupled antennas are located in the far-field area to avoid the influence of "blind area", so that the targets close to the surface of the lining can be inspected, such as the surface aging and damage of some long-standing dilapidated tunnels. on the other hand, due to the fixed railway track position, the stability of the data is improved. If this technology is used in regular monitoring, some changes in the internal structure of the tunnels over time can be studied, and a tunnel disease database can be established to provide a basis for the maintenance and repair of the operating railway.

The test results of tunnels from Shenyang-Dandong railway passenger dedicated line show that: the target of lining thickness, voids, surrounding rock disturbance and lining structure change can be judged by the GPR system, according to the continuity of image, the change of signal amplitude and frequency characteristics and delay, etc. There are still defects in the inspection of the steel structure with the $300 \mathrm{MHz}$ antenna. However, the stability of the detection method described in this paper can provide a fixed detection distance for the high-frequency air-coupled antennas, so the 800-1000 $\mathrm{MHz}$ antenna for steel structure detection will be the focus of further research.

The train-mounted GPR system can quickly detect a large number of tunnels and provide a new solution for regular inspection of operating railways. Although subway tunnels and highway tunnels are different from railway tunnels, this new scheme still has certain research value in these fields. 


\section{Acknowledgments}

It is gratefully acknowledged that the work presented in this paper has been sponsored by the Research on the Application of Full-section Intelligent Detection Technology for Hidden Defects in High-speed Railway Tunnels (2020G08). We thank BeijingShenyang passenger dedicated line Liaoning Co., Ltd for assistance in the implementation of the test and verification of the results.

\section{References}

[1] Asakura T, Kojima Y. Tunnel maintenance in Japan. Tunnelling \& Underground Space Technology Incorporating Trenchless Technology Research. 2003;18(2):161-9.

[2] Investigation and Examination Committee on falling accident of tunnel ceiling plate. Report of Investigation and Examination Committee on tunnel roof falling accident. Final Report. Tokyo: Ministry Of Land, Infrastructure, Transport and Tourism: 2013. 45 p. Japanese..

[3] Zhang S. Study on health diagnosis and technical condition assessment for tunnel lining structure. Beijing: Beijing Jiaotong University; 2012.

[4] European Rail Freight Association Asbl; Netzwerk Europäischer Eisenbahnen e.V; Internationale Vereinigung für den Kombinierten Verkehr Schiene-Straße s.c.r.l. Volkswirtschaftliche Schäden aus dem Rastatt-Unterbruch - Folgenabschätzung für die schienenbasierte Supply-Chain entlang des RhineAlpine Corridor 2017. Draft Final. Hamburg: Hanseatic Transport Consultanc: 2018. 81 p. German.

[5] Lai WW-L, Dérobert X, Annan P. A review of Ground Penetrating Radar application in civil engineering: A 30-year journey from Locating and Testing to Imaging and Diagnosis. NDT and E International. 2018;96:58-78.

[6] Li C, Li MJ, Zhao YG, Liu H, Wan Z, Xu JC, et al. Layer recognition and thickness evaluation of tunnel lining based on ground penetrating radar measurements. Journal of Applied Geophysics. 2011;73(1):45-8.

[7] Lalagüe A, Hoff I, editors. Determination of space behind pre-cast concrete elements in tunnels using GPR. Proceedings of the XIII Internarional Conference on Ground Penetrating Radar; 2010.

[8] Orlando ECM. Evaluation of tunnel stability using integrated geophysical methods. Journal of Applied Geophysics. 2003;52:93-102.

[9] Yu Q-m, Zhou H-l, Wang Y-h, Duan R-x. Quality monitoring of metro grouting behind segment using ground penetrating radar. Construction and Building Materials. 2016;110:189-200.

[10] Zhang F, Xie X, Huang H. Application of ground penetrating radar in grouting evaluation for shield tunnel construction. Tunnelling and Underground Space Technology. 2010;25(2):99-107.

[11] Li S, Li S, Zhang Q, Xue Y, Liu B, Su M, et al. Predicting geological hazards during tunnel construction. Journal of Rock Mechanics and Geotechnical Engineering. 2010;2(3):232-42.

[12] Zan Y, Li Z, Su G, Zhang X. An innovative vehicle-mounted GPR technique for fast and efficient monitoring of tunnel lining structural conditions. Case Studies in Nondestructive Testing \& Evaluation. 2016;6:63-9.

[13] Hugenschmidt J, Kalogeropoulos A. The inspection of retaining walls using GPR. Journal of Applied Geophysics. 2009;67(4):335-44. Doi: 10.1016/j.jappgeo.2008.09.001.

[14] Xiang L, Zhou HL, Shu Z, Tan SH, Liang GQ, Zhu J. GPR evaluation of the Damaoshan highway tunnel: A case study. Ndt \& E International. 2013;59(oct.):68-76.

[15] Tian S, Gong J. Statistics of railway tunnels in China as of end of 2019. Tunnel Construction. 2020;40(2):292.

[16] Uduwawala D, Norgren M, Fuks P, Gunawardena AW. A deep parametric study of resistor-loaded bow-tie antennas for ground-penetrating radar applications using FDTD. Geoence \& Remote Sensing IEEE Transactions on. 2004;42(4):732-42.

[17] Ernenwein EG. Imaging in the ground-penetrating radar near-field zone: a case study from New Mexico, USA. Archaeological Prospection. 2006;13(2):154-6. Doi: 10.1002/arp.286.

[18] Strange AD. Robust thin layer coal thickness estimation using ground penetrating radar. Brisbane: Queensland University; 2007. 